\title{
O Serviço Social no Núcleo de Apoio à Saúde da Família
}

\author{
The Social Work in the Nucleus of Family Health Support
}

\author{
Reginaldo Ghiraldelli* \\ Andreia Oliveira** \\ Michelle da Costa Martins ${ }^{* * *}$
}

\section{Resumo}

No presente artigo expõe-se, de forma aproximativa, os resultados de uma pesquisa realizada sobre o Serviço Social na Atenção Primária à Saúde, com ênfase para a atuação profissional nos Núcleos de Apoio à Saúde da Família (NASFs) no Distrito Federal. A arguição, de base qualitativa, objetivou conhecer as atribuições, competências e condições laborais de assistentes sociais neste espaço sócioocupacional, tendo como ponto de partida os processos de intensificação e precarização do exercício profissional, especialmente, em um contexto de ofensiva neoliberal, medidas de austeridade e ajuste fiscal, com adoção de políticas minimalistas, focalizadas e assistencialistas no trato das expressões da "questão social".

Palavras-chave: Serviço Social. Exercício profissional. Saúde. Atenção Primária à Saúde. Núcleo de Apoio à Saúde da Família (NASF).

\begin{abstract}
This article presents, in an approximate way, the results of a survey carried out on Social Work in Primary Health Care, with emphasis on professional performance in the Family Health Support Centers (NASFs) in the Federal District. The research, with a qualitative basis, aimed to know the attributions, competences and working conditions of social workers in this socio-occupational space, taking as a starting point the intensification and precarious processes of professional practice, especially in a context of neoliberal offensive, measures of austerity and fiscal adjustment, with the adoption of minimalist, focused and assistentialist policies in dealing with the expressions of the "social issue".
\end{abstract}

Keywords: Social Work. Professional work. Health. Primary Health Care. Family Health Support Center (NASF).

\footnotetext{
* Docente do Departamento de Serviço Social e do Programa de Pós-Graduação em Política Social da Universidade de Brasília (UnB). Assistente social, mestre e doutor em Serviço Social pela Unesp. Coordena o Grupo de Estudos e Pesquisas sobre Trabalho, Sociabilidade e Serviço Social (TRASSO).

** Docente do Departamento de Serviço Social e do Programa de Pós-Graduação em Política Social da Universidade de Brasília (UnB). Assistente social, mestre em Saúde Pública (UFSC) e doutora em Serviço Social pela Pontifícia Universidade Católica de São Paulo. Realiza estágio de Pós-Doutorado pela Universidade de Alicante (Espanha) com bolsa da Fundação de Amparo à Pesquisa do Distrito Federal (FAP-DF). Pesquisadora do Grupo de Estudos e Pesquisas sobre Trabalho, Sociabilidade e Serviço Social (TRASSO).

${ }^{* * *}$ Assistente social da Secretaria de Estado de Saúde do Distrito Federal (SES-DF) e membro do Grupo de Estudos e Pesquisas sobre Trabalho, Sociabilidade e Serviço Social (TRASSO).
} 


\section{Introdução}

Este artigo apresenta, em linhas gerais, uma análise sobre as atribuições, competências e condições de trabalho de assistentes sociais nas políticas sociais, com ênfase na saúde, tendo como referência o Núcleo de Apoio à Saúde da Família (NASF), a partir do cenário e particularidades do Distrito Federal. A análise parte de premissas como o processo de reestruturação produtiva no capitalismo mundializado e financeirizado, sob a égide da ofensiva neoliberal, em um contexto histórico e conjuntural de aprofundamento das medidas de austeridade e ajuste fiscal. Tal cenário, orientado pelas contrarreformas ${ }^{1}$ implementadas no Brasil nos últimos anos, possibilita compreender os limites e possibilidades postos no cotidiano do exercício da profissão nos seus diversos espaços sócio-ocupacionais, pois provoca incidências diretas tanto para a direção das ações profissionais, quanto para o alcance dos direitos e políticas sociais pela população.

O exercício profissional de assistentes sociais é compreendido, na divisão social e técnica do trabalho, como especialização do trabalho coletivo (IAMAMOTO, 2009), no estágio monopolista do capitalismo, sendo legitimado e instaurado diante da intervenção do Estado por meio de respostas às expressões da "questão social" pela via das políticas sociais².

Neste artigo são apresentados resultados aproximativos de uma pesquisa realizada no Distrito Federal com assistentes sociais inseridos nos Núcleos de Apoio à Saúde da Família (NASFs). O estudo, de natureza qualitativa, foi desenvolvido por meio de levantamento bibliográfico, documental e pesquisa empírica, e contou com o apoio da Gerência de Serviço Social da Secretaria de Estado de Saúde do Distrito Federal, o que permitiu o acesso e contato com assistentes sociais inseridos nesse espaço sócio-ocupacional. A coleta de dados em campo foi realizada entre os anos de 2015 e 2017 com assistentes sociais inseridos nos Núcleos de Apoio à Saúde Família (NASFs) do DF e consistiu em dois momentos: aplicação de questionários on-line (Plataforma Google) e realização de entrevistas semiestruturadas, que foram transcritas, interpretadas e analisadas ${ }^{3}$. De um conjunto de 10 profissionais com

\footnotetext{
${ }^{1}$ Termo utilizado por entender que as ações e medidas adotadas expressam mudanças regressivas, ou seja, não são "reformas" progressivas.

2 Com base em lamamoto (2009, p. 27), “A questão social é indissociável da sociabilidade capitalista e envolve uma arena de lutas políticas e culturais contra as desigualdades socialmente produzidas. [...] de uma dimensão estrutural enraizada na produção social contraposta à apropriação privada do trabalho, 'a questão social' atinge visceralmente a vida dos sujeitos numa luta aberta e surda pela cidadania". No contexto de mundialização financeira do capitalismo, "[...] a 'questão social' é mais do que pobreza e desigualdade. Ela expressa a banalização do humano" (IAMAMOTO, 2009, p. 31).

${ }^{3}$ O projeto de pesquisa foi submetido e aprovado pelo Comitê de Ética em Pesquisa (CEP), conforme Protocolo no 1156935 , relatado em 31/07/2015.
} 
atuação nos Núcleos de Apoio em Saúde da Família (NASFs), 06 assistentes sociais responderam ao questionário on-line e 02 participaram das entrevistas semiestruturadas.

Tendo em vista que a área da saúde é um dos espaços sócio-ocupacionais de maior absorção de assistentes sociais no mundo do trabalho, essa pesquisa justifica-se pela necessidade de aproximar-se do cotidiano profissional tendo como lócus os Núcleos de Apoio à Saúde da Família em uma realidade delimitada, no caso do Distrito Federal.

Conforme esboçado por lamamoto (2009), assistentes sociais no Brasil são prevalentemente servidores públicos, com destaque para a atuação na área da saúde. Ou seja, as políticas sociais tornam-se espaços privilegiados da atuação profissional, como é o caso da política de saúde.

\section{Natureza do Serviço Social e condições de trabalho de assistentes sociais}

O objeto de investigação e intervenção profissional do Serviço Social são as múltiplas expressões da "questão social" e, sendo assim, assistentes sociais, trabalhadores assalariados e especializados (RAICHELIS, 2011) participam, com incidência direta e objetiva, nos processos de reprodução material e nos modos de vida da classe trabalhadora por meio de políticas públicas, direitos sociais, serviços, benefícios e programas, com destaque para a seguridade social,

\footnotetext{
A natureza da atividade profissional do assistente social advém de sua inserção nas estruturas institucionais prestadoras de serviços sociais, que perfazem os aparatos públicos e privados viabilizadores das políticas sociais. Mais precisamente, é uma profissão que se desenvolve na esfera dos serviços, particularmente dos serviços sociais, aqueles voltados para o atendimento das necessidades de reprodução (material e ideológica) da força de trabalho (TRINDADE, 2015, p. 124).
}

Nesse sentido, compreender o exercício profissional no âmbito da saúde e sua autonomia relativa (IAMAMOTO, 2009), com ênfase para a sua natureza investigativa e interventiva, a partir da sua dimensão assalariada, requer situar a inserção de assistentes sociais em espaços sócio-ocupacionais contraditórios, tensos, com limites e possibilidades, o que exige da categoria uma inserção crítica e qualificada no mundo do trabalho.

O Serviço Social, reconhecido como profissão da área da saúde ${ }^{4}$, tem nesta área um dos seus espaços de inserção profissional, mas, considerando que os assistentes sociais não

\footnotetext{
${ }^{4}$ A Resolução no 218, de 6 de março de 1997, do Conselho Nacional de Saúde (CNS) regulamenta as profissões de saúde e, dentre elas, o Serviço Social. São reconhecidas as seguintes categorias profissionais: Assistentes
} 
são exclusivos da saúde, se inserem também em outras áreas, como com a assistência social, à educação, à habitação, à previdência social, à política urbana e rural, com o sociojurídico, dentre outros.

Inúmeros são os desafios encontrados no cotidiano de trabalho de assistentes sociais, como é o caso da saúde, dentre os quais estão a necessidade de identificar e distinguir criticamente as requisições e demandas institucionais à luz das atribuições e competências profissionais. De modo geral, as demandas institucionais que se apresentam na cotidianidade se pautam em ações fragmentadas, emergenciais, pontuais, imediatas, desvinculadas das determinações sócio-históricas da vida social em sua totalidade, o que pode corroborar para uma apreensão acrítica e meramente burocrática das múltiplas expressões da "questão social". Por isso, a inserção crítica e qualificada no mundo do trabalho possibilita a minimização de simplificações na atuação profissional baseadas em manuais, normas, roteiros, modelos de ação e procedimentos padronizados.

O exercício profissional de assistentes sociais, situado na sociabilidade capitalista contemporânea, depara-se com as transformações ocorridas no mundo do trabalho que provocam efeitos danosos para a classe trabalhadora e, nesse caso, para assistentes sociais. A lógica baseada na mensuração das ações segundo metas, resultados, produtividade, controle, cobranças, resolutividade e polivalência, tem ocasionado a deterioração das condições de trabalho e da vida de profissionais, tendo em vista os processos de precarização, intensificação e adoecimento laboral.

Além do mais, as medidas de austeridade e ajuste fiscal, aprovadas no governo Michel Temer, como é o caso da Emenda Constitucional no 95 de 2016, que estabelece um regime fiscal baseado no teto de gastos no âmbito da seguridade social, contribuem para o sucateamento, fragmentação e redução dos serviços sociais e das políticas públicas. Soma-se a esse retrocesso o aumento exponencial do desemprego e do empobrecimento da população, que provocam a expansão de demandas profissionais, em um quadro de contenção, cortes do orçamento público para as políticas sociais e número reduzido de assistentes sociais para o atendimento das demandas e requisições institucionais que se ampliam.

Sociais, Biólogos, Profissionais de Educação Física, Enfermeiros, Farmacêuticos, Fisioterapeutas, Fonoaudiólogos, Médicos, Médicos Veterinários, Nutricionistas, Odontólogos, Psicólogos e Terapeutas Ocupacionais. 
O assistente social é um profissional que, para além das requisições institucionais, baseadas em demandas e respostas formais, imediatas e burocráticas, apreende criticamente a realidade social, tendo em vista as forças em presença, as contradições e as tensões estabelecidas entre a dimensão assalariada do trabalho e os princípios norteadores do projeto ético-político, orientado pela defesa da democracia, da liberdade, da autonomia, dos direitos sociais universais, da qualidade dos serviços prestados e do repúdio a todas as formas de discriminação e opressão de gênero, raça, etnia, credo e orientação sexual. Para tanto, em suas ações, estes profissionais encontram respaldo na Lei de Regulamentação da Profissão no 8662 de 1993 e no Código de Ética, também de 1993.

As ações profissionais, que envolvem o processo investigativo-interventivo, a formulação, o planejamento, a gestão, a execução de serviços e políticas sociais, os encaminhamentos, a orientação aos indivíduos, grupos e famílias, são permeadas e orientadas pelos princípios e direção do projeto ético-político, e podem ser compreendidas de forma ampliada como,

[...] as atribuições que viabilizam as respostas dos profissionais às requisições colocadas pelas demandas institucionais, como parte da prestação de serviços sociais. Essas ações materializam o caráter interventivo do Serviço Social e dentre as mais comuns estão: executar, orientar, agrupar, providenciar, acompanhar, socializar, coordenar, planejar, pesquisar, monitorar, supervisionar, organizar e administrar, estudar e analisar, emitir parecer, assessorar, consultorar. [...] Esses conteúdos estão permeados pelas concepções teóricas, pela perspectiva éticopolítica, as quais fundamentam e direcionam as escolhas profissionais (TRINDADE, 2012, p. 70).

Com base nas dimensões teórico-metodológicas, ético-políticas e técnico-operativas, assistentes sociais estabelecem, a partir de instrumentos, técnicas, métodos e recursos interventivos à finalidade da ação profissional. Desse modo, parte-se da compreensão de que não há neutralidade nas ações profissionais. Essas ações são orientadas e direcionadas por valores ético-morais e compromissos sociopolíticos, podendo contribuir para o fortalecimento de projetos societários vinculados aos interesses e necessidades da classe trabalhadora, mas podem atender, ao mesmo tempo, aos anseios e demandas do capital, pois,

[...] o Serviço Social se afirma como parte integrante do aparato institucional estatal ou privado, constituindo um dos mecanismos institucionais mobilizados pela burguesia, para legitimação de seu poder de classe, no cenário contraditório em que se movem as classes sociais antagônicas. Os profissionais são assalariados e participam da criação de condições favorecedoras da reprodução da força de trabalho [...] (TRINDADE, 2015, p. 123-124). 
O exercício profissional de assistentes sociais nas instituições públicas e privadas está permeado pelas "[...] demandas sociais, as demandas institucionais, as requisições profissionais e as respostas profissionais" (TRINDADE, 2015, p. 123).

Ainda estão presentes nas ações profissionais, sobretudo em um contexto de burocratização, de pragmatismo, de cobranças, de cumprimento de metas e de produtividade, os atendimentos focalizados, individualizados, imediatos, meramente administrativos e residuais, o que contribui para obstaculizar ações contínuas, educativas e coletivas voltadas para formas de organização, mobilização e participação social.

Além disso, assistentes sociais vivenciam cotidianamente condições precárias e intensificadas de trabalho (RAICHELIS, 2011; TRINDADE, 2015), diante do número reduzido de profissionais para o atendimento das demandas cada vez mais ampliadas e complexificadas, da fragilização dos vínculos empregatícios, da baixa remuneração, da desvalorização profissional, da sobrecarga, da polivalência, da ausência ou inadequação de espaços e ambientes salubres para a realização das ações como salas individuais, salas para reuniões e atividades de grupos.

Além disso, esses espaços sócio-ocupacionais também são caracterizados na maioria das situações por ambientes com precária iluminação, ausência de ventilação, de recursos materiais e financeiros, e de transporte para a realização de atividades como visitas domiciliares e institucionais. Todos esses indicadores repercutem direta e negativamente nas condições laborais de assistentes sociais e, em muitos casos, obstaculizam as ações profissionais, além de incidir na saúde profissional, desencadeando desgastes físicos e emocionais decorrentes da precarização do trabalho. Como componente adicional, a maioria de assistentes sociais são mulheres, o que significa a dupla ou tripla jornada de trabalho diante da divisão sexual do trabalho, ou seja, mais sobrecarga, mais intensidade, mais trabalho (RAICHELIS, 2011).

Também está presente nesse cenário a ampliação de cursos de graduação em Serviço Social, diante de um processo intenso de mercantilização da educação e, concomitantemente, de ampliação do mercado de trabalho, cada vez mais caracterizado pela desvalorização e baixo reconhecimento profissional. Nesse quadro, assistentes sociais passam a compor o exército de sobrantes no capitalismo contemporâneo. 


\section{O Núcleo de Apoio à Saúde da Família (NASF): breve consideração}

A partir do enfoque deste artigo, de abordar a inserção profissional de assistentes sociais nos Núcleos de Apoio à Saúde da Família (NASFs), como um dos espaços sócioocupacionais possíveis de atuação na área das políticas de seguridade social, cabem algumas considerações acerca do NASF.

A Política Nacional de Atenção Básica (BRASIL, 2011) ${ }^{5}$, com base em seus princípios e diretrizes, pressupõe abordagem integradora, a qual abrange, de modo conjunto, ações individuais e coletivas de promoção da saúde; de proteção da saúde e da prevenção de agravos; de recuperação da saúde, mediante o diagnóstico e tratamento da doença, a reabilitação, redução de danos e a manutenção da saúde.

No contexto de reordenamento da atenção à saúde, a perspectiva da saúde da família foi reconhecida como eixo prioritário, norteadora da expansão dos sistemas locais de saúde. De modo decorrente, a Estratégia de Saúde da Família foi instituída como instrumento condutor da consolidação da Atenção Básica no Sistema Único de Saúde (BRASIL, 2011).

A Estratégia de Saúde da Família (ESF) emerge como modelo de organização da atenção primária à saúde e da atenção básica no Brasil, com o objetivo de catalisar o processo saúde-doença dos indivíduos na instância da família e na esfera das comunidades.

Em 2008, foi instituído o Núcleo de Apoio à Saúde da Família (NASF) ${ }^{6}$, constituído por profissionais de diferentes áreas do conhecimento, com o objetivo de apoiar o trabalho cotidiano dos integrantes das equipes de saúde da família em seu território, além de compartilhar, com as equipes, as suas práticas de saúde.

Esses Núcleos foram concebidos para prestar apoio em oito áreas estratégicas da atenção à saúde: atividade física e práticas corporais; práticas integrativas e complementares; reabilitação; alimentação e nutrição; saúde mental; serviço social; saúde da criança, do adolescente e do jovem; saúde da mulher; e assistência farmacêutica.

\footnotetext{
${ }^{5}$ Além da consolidação de uma base jurídica na saúde, foram introduzidas iniciativas de reorientação do modelo assistencial, com o propósito de contribuir à reordenação do modelo assistencial hegemônico na saúde baseado na concepção biológica e curativa. Assim, foram instituídos o Programa de Agentes Comunitários de Saúde (PACS) em 1991, e o Programa Saúde da Família (PSF) introduzido em 1994. Outra medida tomada pelo Estado brasileiro foi o advento em 2006, da Política Nacional de Atenção Básica - PNAB (BRASIL, 2006), fundamentada na atenção primária à saúde e na perspectiva da abordagem da saúde da família e da comunidade, com entendimento da saúde como resultante de determinações sociais a serem providos na esfera dos direitos sociais. Na PNAB 2006 foi estabelecida a Estratégia de Saúde da Família como eixo de reorganização da Atenção Básica tradicional.

${ }^{6} \mathrm{O}$ projeto do NASF foi regulamentado em portaria de 2008 (BRASIL, 2008), posteriormente revogada. A continuidade do projeto foi regulamentada pelo órgão federal de saúde em 2011 (BRASIL, 2011).
} 
Desde a promulgação da Lei Orgânica da Saúde, em 1990, que estrutura e consolida o Sistema Único de Saúde (SUS), as várias medidas e mecanismos introduzidos para a reorganização da assistência à saúde - PACS, PSF, equipes de saúde da família, Política Nacional de Atenção Básica, Estratégia de Saúde da Família, Núcleo de Saúde da Família NASF, representam instâncias de materialização do apoio matricial.

O apoio matricial prevê a integração entre profissionais de saúde que trabalham com um objetivo comum (BRASIL, 2014) e se dá por meio do contato direto entre equipe de saúde e apoiadores. Esse contato pode ocorrer tanto em encontros regulares, quanto em encontros periódicos. Os profissionais responsáveis pelo apoio matricial proporcionam apoio especialmente às equipes de saúde da família. Embora não mantenham, necessariamente, relação direta e constante com os usuários dos serviços de saúde da unidade de saúde da família, essas relações também são estabelecidas no apoio matricial. Ou seja, duas ou mais equipes de profissionais de saúde atuam de forma compartilhada, por meio de uma ação que é, ao mesmo tempo, pedagógica e terapêutica (CAMPOS, 1999). Com isso, o apoio matricial apresenta duas dimensões: a assistencial, a qual produz ação clínica diretamente com os usuários do serviço de saúde; e a ação técnico-pedagógica, baseada na dimensão educativa com a equipe e para a equipe, tendo como objetivo contribuir para a superação do modelo biológico hegemônico.

Com isso, desafios colocados na concepção e proposta do NASF consiste na superação e rupturas com formas e modelos assistenciais de saúde voltados para a lógica curativa, hospitalocêntrica, biologizante e mercantil, abrindo caminho para uma perspectiva de ação multiprofissional, participativa, integradora e orientada para a defesa dos direitos sociais e por valores universalistas. Nesse sentido, dentre os profissionais que se inserem no NASF, estão os assistentes sociais, que possuem atribuições e competências fundamentais para potencializar essa dimensão educativa, participativa, de mobilização e de defesa dos direitos sociais da população a partir de uma intervenção crítica, qualificada, competente e direcionada pelos princípios do SUS, da Reforma Sanitária e do projeto ético-político profissional. Tal realidade demonstra a necessidade e relevância de estudos que abordem o exercício profissional de assistentes sociais nesses espaços ocupacionais.

Somado a tais desafios estão aqueles oriundos de um conjunto de medidas governamentais que aprofundaram os retrocessos políticos e sociais do Estado brasileiro 
iniciados em 2016 com o golpe jurídico parlamentar, em especial nos serviços de saúde, educação, previdência social e direitos trabalhistas.

Em relação à Atenção Primária à Saúde (APS), o conjunto de mudanças colocam em risco os avanços sanitários e a sustentabilidade dos pilares que norteiam o modelo neste nível de atenção, especialmente por meio da Estratégia de Saúde da Família (ESF). As alterações trazem mudanças no escopo da Política Nacional de Atenção Básica para um modelo clinico e individual, além de afetar outras dimensões como da participação social, familiar e comunitária, estabelecidas em normativas legais, dentre as quais se destacam: Portaria no 2.436/2017 que prevê uma nova Política Nacional de APS (BRASIL, 2017); proposta de Carteiras de Serviços para a APS (BRASIL, 2019b); criação da Agência de Desenvolvimento da APS (ADAPS) por meio da Medida Provisória 890/2019 (BRASIL, 2019a); mudança de financiamento da APS previsto na Portaria no 2.979/2019 (BRASIL, 2019d).

Notadamente sobre o NASF, o novo modelo de financiamento revogou normas anteriores, dentre elas os parâmetros e custeio de tais núcleos de apoio. O detalhamento de tais mudanças foi explicitado pelo Ministério da Saúde na Nota Técnica no 3/2020DESF/SAPS/MS (BRASIL, 2019c), com previsão de extinção do incentivo financeiro federal para que os municípios componham as equipes do NASF. Com isso, a continuidade do NASF está sob risco, mas não somente, pois o que está sob risco de extinção é a prioridade da Estratégia de Saúde da Família e seu modelo assistencial com equipe multiprofissional e abordagem territorial e comunitária.

\section{O exercício profissional de assistentes sociais nos Núcleos de Apoio à Saúde da}

\section{Família (NASFs)}

O exercício profissional de assistentes sociais não pode ser apreendido fora do processo histórico, individualizado e isolado da totalidade da vida social, mas ao contrário, a profissão se constitui e se dinamiza na trama das relações sociais. Ou seja, analisar e problematizar o exercício profissional na contemporaneidade requer considerar a natureza da

profissão, sua gênese, legitimidade, significado sócio-histórico (IAMAMOTO, 2009), as determinações, interesses e contradições que permeiam as relações sociais - capitalistas marcadas pelo antagonismo de classes, o papel do Estado na correlação de forças sociais, além da apreensão crítica das expressões da "questão social". 
O exercício profissional pressupõe fundamentação teórica, ética e política constante, o que significa a necessidade da formação permanente, não como treinamento para o atendimento rotineiro, tecnicista e burocrático, mas para o aprimoramento intelectual e capacidade de apreensão crítica e histórica da realidade social a partir de suas múltiplas e complexas determinações. Isso exige da profissão uma análise fecunda, crítica e prospectiva da realidade social sob o prisma da totalidade.

A fundamentação e o aprimoramento teórico-intelectual contribuem para a qualificação profissional, o que possibilita e viabiliza respostas às demandas sociais de forma competente e crítica do Serviço Social diante das requisições emergentes. Também contribuem para o não obscurecimento e para a não fragmentação dos processos e naturalização dos fenômenos sociais, tendo em vista que a vida cotidiana é marcada pela imediaticidade, espontaneidade e repetições, levando às práticas reiterativas.

Isso não significa negar e anular a imediaticidade, até porque a aparência fenomênica dos fatos imediatos que se apresentam na cotidianidade das ações profissionais são momentos constitutivos e constituintes do movimento histórico e dialético da realidade social. O desafio é a ultrapassagem da imediaticidade, de forma a compreender e apreender as mediações postas na dinâmica da vida social em sua totalidade e historicidade, o que não significa e não implica a anulação daquilo que se apresenta no nível aparente e imediato. Ao contrário, pois as mediações conjugam a dimensão da singularidade e da universalidade, o que significa que: a universalidade se singulariza e a singularidade se universaliza. Isso pressupõe um exercício profissional que se aproprie da razão dialética, histórica e crítica, tendo como direcionamento das ações o projeto ético-político profissional (PONTES, 2009).

Por isso, toda ação profissional possui uma direção, um sentido, uma finalidade e uma intencionalidade, ou seja, não há neutralidade no exercício profissional de assistentes sociais, já que suas ações são emaranhadas de sentido valorativo e ideopolítico. O projeto profissional abrange dimensão teórica, técnica e ética. Teórica, porque se fundamenta em um conhecimento acumulado e apreendido sobre a realidade social; técnica porque o exercício profissional se materializa no cotidiano a partir da operacionalização das ações; e ética, tendo em vista aos valores, intencionalidades e finalidades que norteiam a atuação profissional,

No caso de uma profissão, a ética congrega duas dimensões. A primeira refere-se à reflexão teórica da própria profissão sobre os fundamentos da moralidade, ou seja, os valores. A segunda é uma resposta consciente da categoria profissional, indicando 
um dever ser, que se materializa pela construção, por parte dos sujeitos da profissão, de parâmetros de conduta, ou seja, o código de ética (MATOS, 2013, p. 96).

Assim, o exercício profissional deve ser compreendido na sua dimensão teleológica, o que significa considerar a finalidade e a intencionalidade de ações profissionais conscientes, ou seja, permeadas por valores éticos, compromissos políticos, referencial teórico, postura investigativa e interventiva a partir de objetivos a serem alcançados. Isso significa que as ações profissionais são planejadas, dotadas de alternativas e de possibilidades (SANTOS, 2010).

Além disso, o exercício profissional se realiza a partir de três condições básicas, que são: o diploma de nível superior, ou seja, a realização do curso de graduação em Serviço Social; o registro profissional no órgão competente, no caso o Conselho Regional de Serviço Social (CRESS) do estado/jurisdição onde o assistente social exercerá a atividade profissional, considerando que a profissão é regulamentada; seguido pela contratação/venda do seu trabalho, tendo em vista as relações sociais capitalistas baseadas no regime de assalariamento (TRINDADE, 2015).

O exercício profissional se realiza no cotidiano contraditório e antagônico da sociabilidade capitalista e deve ser impulsionado pela perspectiva crítica, comprometido com os interesses e necessidades da classe trabalhadora, ou seja, com os direitos sociais, com a qualidade dos serviços prestados e, além disso, com a emancipação política e humana.

Diante dessas considerações, são apresentados resultados da pesquisa empírica realizada no Distrito Federal, tendo como enfoque as atribuições e competências profissionais de assistentes sociais na Atenção Primária à Saúde com ênfase para os Núcleos de Apoio à Saúde da Família (NASFs), abrangendo as condições de trabalho, os instrumentos, técnicas e procedimentos presentes no cotidiano profissional.

Analisar as particularidades do exercício profissional de assistentes sociais na área da saúde significa compreendê-lo a partir de sua inserção no trabalho coletivo, tendo como pressuposto o conceito ampliado de saúde e as determinações sociais do processo saúdedoença.

Com base nas breves considerações sobre a Atenção Primária à Saúde, o Estado brasileiro foi estabelecendo, desde a promulgação do Sistema Único de Saúde, em 1990, políticas públicas de saúde de reordenamento e estruturação do modelo assistencial, na perspectiva da saúde da família e da comunidade, embora de modo não linear e sob injunções de embates e disputas entre projetos de saúde diversos e divergentes. Diferentes perspectivas 
de organização dos cuidados primários em saúde vêm sendo incorporadas nas ações de saúde, ainda que sejam observadas as denominações genéricas de Programa de Saúde da Família (PSF) ou de Estratégia de Saúde da Família - ESF (MENDES, 2015).

O que se observa nos serviços de atenção à saúde no Distrito Federal, de forma semelhante à trajetória das grandes cidades e regiões metropolitanas do Brasil, é um funcionamento da saúde pautado na prática medico-curativa e hospitalocêntrica ${ }^{7}$. Essa forma de atenção à saúde contribui para os constantes, descontinuados e diferentes ciclos de modelos definidos para a Atenção Primária à Saúde, assumidos em cada edição trienal do Plano de Saúde do Distrito Federal. Um dos desafios para a Estratégia de Saúde da Família consiste na reversão do modelo de assistência à saúde, medicamentoso-curativo e tecnológico-hospitalocêntrico, condizente com a lógica mercantil, de forma a construir um direcionamento integrador, resolutivo, multiprofissional, voltado para a efetivação da saúde como direito social universal.

Os dois últimos Planos Distritais de Saúde do Distrito Federal, referentes ao triênio anterior e o atual, vêm sinalizando para um modelo de Atenção Primária à Saúde ordenado nos moldes da Estratégia de Saúde da Família. O Plano Distrital 2012-2015 acenou, em suas diretrizes, para a estruturação do atendimento em Atenção Primária à Saúde, com ênfase na Estratégia de Saúde da Família. No Plano Distrital 2016-2019, essa estruturação é reforçada ao ser definido o fortalecimento da política de Atenção Primária à Saúde com foco na expansão da Estratégia de Saúde da Família.

No ano de 2016, foi lançado o Programa Brasília Saudável - A Atenção Primária à Saúde resolutiva no Distrito Federal, no qual está proposto o fortalecimento da Atenção Primária no Distrito Federal. O documento do Programa Brasília Saudável aponta a baixa cobertura por parte da Estratégia de Saúde da Família no DF, de apenas 30,7\%. A implantação do Programa está prevista para ocorrer até 2018 , de forma progressiva, nas Regiões de Saúde estabelecidas por meio do Decreto 37.057, de 14 de janeiro de 2016.

O Programa Brasília Saudável proporcionou embasamento para que, no ano de 2017, o Distrito Federal implantasse um processo denominado CONVERTE, referente à modificação do modelo assistencial tradicional de atenção à saúde para uma perspectiva fundamentada

\footnotetext{
${ }^{7}$ A retrospectiva dos 47 anos de gestão da saúde no Distrito Federal mostra investimentos maciços de recursos financeiros e políticos na construção de hospitais. Evidencia, ainda, que as iniciativas para fortalecer a Atenção Primária à Saúde foram descontínuas e desarticuladas da rede de serviços de média e alta complexidade, com reduzida oferta de capacitação profissional, justificada pela necessidade de garantir a retaguarda da atenção hospitalar (GÖTTEMS et al., 2009).
} 
na Estratégia de Saúde da Família, tendo em vista a existência concomitante de ambas as modalidades na Atenção Primária à Saúde.

O marco institucional do processo CONVERTE se deu com a publicação da Portaria no 77, de 2017, por meio da qual foi estabelecida a Política de Atenção Primária à Saúde do Distrito Federal, fundamentada na Estratégia de Saúde da Família (ESF), e também por intermédio da Portaria no 78/2017, com a qual foi regulamentado o processo de conversão da Atenção Primária à Saúde ao modelo da Estratégia de Saúde da Família do Distrito Federal.

De acordo com as novas regulamentações, os profissionais da Atenção Primária à Saúde (médicos, enfermeiros, técnicos em enfermagem e agentes comunitários em saúde) tiveram acesso à capacitação para o desenvolvimento da prática da Estratégia de Saúde da Família. Os profissionais de saúde que não participassem da capacitação, ou que tivessem obtido nota de aproveitamento insuficiente, e os médicos que não solicitassem a mudança de área para Medicina de Família e Comunidade, seriam movimentados para unidades de outros níveis de atenção, não necessariamente na mesma região de saúde.

A estruturação e a operacionalização dos Núcleos Ampliados de Saúde da Família e Atenção Básica (NASF-AB) foram regulamentadas pela Portaria no 489/2018, na qual foi estabelecido que a equipe do NASF-AB deve contar com, no mínimo, 5 servidores de profissões distintas, considerando a definição do Código Brasileiro de Ocupações - CBO na área de saúde, das seguintes especialidades: Farmácia, Fonoaudiologia, Fisioterapia, Nutrição, Psicologia, Serviço Social e Terapia Ocupacional.

No Distrito Federal, a saúde tem um histórico relevante no que se refere à inserção de assistentes sociais na área. Todavia, programas circunscritos à concepção da Estratégia de Saúde da Família podem ser considerados como um espaço ainda não efetivamente ocupado, no âmbito do DF, pela categoria profissional de assistentes sociais.

De acordo com informações disponibilizadas pela Gerência de Serviço Social da Secretaria de Estado de Saúde do Distrito Federal (SES-DF), na Semana do/a Assistente Social em $2018^{8}$, o número de assistentes sociais em atuação na saúde pública do Distrito Federal era de 271 profissionais. Desse total, 69 desenvolviam atividades nas Unidades Básicas do Sistema Único de Saúde, o que equivale a apenas $25 \%$ do total de profissionais do Serviço Social em exercício na área da saúde no Distrito Federal. Desse total, 10 assistentes sociais estão inseridos nos Núcleos de Apoio à Saúde da Família (NASFs).

\footnotetext{
${ }^{8}$ Evento anual promovido pela SES-DF, em maio de 2018.
} 
Com base nas informações dos questionários respondidos por 6 assistentes sociais e outras 2 que participaram da entrevista semiestruturada e que atuam no NASF no Distrito Federal, identifica-se o respectivo perfil profissional: Todas são mulheres, com faixa etária de 31 a 56 anos, e possuem renda mensal individual de 7 a 13 salários mínimos. Das 8 respondentes, 2 possuem apenas a graduação e as demais possuem especializações na área da saúde (saúde mental e saúde da família) e da gestão social. O tempo de atuação como assistente social varia de 8 anos a mais de 20 anos. Todas as assistentes sociais participantes da pesquisa são concursadas e possuem vínculo estatutário, porém possuem jornada de trabalho semanal de 40 horas, o que demonstra os desafios para o cumprimento da Lei $n$ o 12.317 de 2010 , que estabelece 30 horas semanais de trabalho para assistentes sociais sem redução de salário.

A partir das entrevistas, a concepção político-pedagógico de natureza integradora e interdisciplinar, contemplada na proposta de apoio matricial do NASF (CAMPOS, 1999; CAMPOS; DOMITTI, 2007), apresenta condições potenciais de favorecer a atuação profissional em saúde, nos moldes da concepção da atenção primária à saúde. Isso se expressa nas narrativas dos sujeitos da pesquisa:

É um núcleo que tem vários profissionais de diferentes saberes, diferentes formações que dão apoio matricial às equipes de saúde da família, equipes básicas que geralmente tem médico, enfermeiro, agente comunitário de saúde, técnico em enfermagem e o pessoal da saúde bucal. Então, o NASF aqui especificamente, ele está composto por mim que sou assistente social, tem a fonoaudióloga, tem um pediatra, tem dois nutricionistas, e tinha uma terapeuta ocupacional, que agora foi para a gerência. Muda de acordo com as especialidades de cada NASF. Cada um vai ter um jeito, mas existem várias especialidades: psicólogo, psiquiatra, a gente tinha homeopata também uma época, fisioterapeuta, até educador físico (Assistente Social NASF 1).

Fazemos reuniões de matriciamento, a parte que mais trabalhamos em equipe, por exemplo. Às vezes é um problema psicológico, uma coisa puxa a outra, então tem que avaliar como um todo. Muitas equipes já tem esse entendimento. A gente tem aqui o Projeto Terapêutico Singular, que é um projeto que você faz daquele paciente, quando é um paciente que engloba mais de um, dois, três profissionais. A gente tenta fazer esse projeto, não é uma coisa que a gente ainda tá atuando muito, porque falta tempo de sentar e planejar aquele paciente, mas estamos tentando adaptar. Então trabalhamos mais em equipe (Assistente Social NASF 2).

O matriciamento às Equipes de Saúde da Família, assume a centralidade das ações do NASF. Trata-se de um traço desse serviço que o diferencia dos demais, no âmbito da Atenção Primária à Saúde. Essa característica também marca as ações e atividades do Serviço 
Social, realizadas predominantemente em articulação com a equipe do NASF, Equipe de Saúde da Família e com a rede de proteção social local. A incorporação de tal proposta pode favorecer ao processo de suplantação do modelo hegemônico em saúde, pautado no saber biomédico e norteador da maior parte das ações em curso no setor saúde do país e do DF. Assim, a perspectiva do apoio matricial também pode fortalecer à incorporação da abordagem interdisciplinar e da integralidade da saúde na atuação das Equipes da Atenção Primária à Saúde do Distrito Federal, no sentido de favorecer a superação da lógica de funcionamento historicamente vivenciada, referenciada no modelo biomédico hegemônico na saúde.

A fala dos profissionais indica que a ênfase do trabalho do Núcleo de Apoio à Saúde da Família (NASF) volta-se para o "apoio" às Equipes de Saúde da Família e, desse modo, diferencia-se de outras ramificações da atenção primária à saúde, nas quais o destaque recai no atendimento direto aos usuários. Esse "apoio" aparece caracterizado, principalmente, como apoio institucional e/ou apoio matricial, de modo que as ações desenvolvidas pelo Serviço Social se vinculam a essa atividade, conforme consta na seguinte fala:

A gente tem que estar articulado às equipes, e que são a referência das famílias. $A$ gente não é referência. A gente não é porta de entrada, é de apoio matricial. Mas existe atendimento individual, existe demanda espontânea, existe visita, todas essas coisas que os profissionais fazem. A diferença é que a gente tenta fazer isso sempre junto com as equipes. É tudo discutido em conjunto, para qualificar, não ficar só em atendimentos pontuais, sem interlocução de nada (Assistente Social NASF 1).

Entrelaçada a essa discussão do "apoio" e matriciamento, aparece a perspectiva de "empoderamento", ou seja, o matriciamento é entendido também como uma forma da equipe do NASF "empoderar" os profissionais das Equipes de Saúde da Família, por meio de conhecimentos que possam contribuir nos atendimentos realizados pelos profissionais.

\footnotetext{
Matriciamento é essa ideia de empoderar as equipes para elas conseguirem lidar com demandas parecidas que vão surgindo, de acordo com cada conhecimento que a gente tem enquanto profissionais de especialidades específicas (Assistente Social NASF 1).

Então aí não tem mais essa questão de encaminhamento. Agora quando o paciente chega e fala, ou o médico fala: eu preciso da nutricionista, ou da fisioterapeuta, a gente tenta empoderar a equipe. Às vezes é um exercício que você mesmo consegue passar para o paciente. Olha é assim, a gente orienta, o negócio do passe livre, a gente orienta, porque da próxima vez eles nem vão acionar a gente por causa disso. Então a gente tenta empoderar a equipe em alguns conhecimentos básicos. Quando foge da área realmente, que é uma coisa que você precisa especificar, a gente tenta marcar um atendimento (Assistente Social NASF 2).
} 
Assistentes sociais nos Núcleos de Apoio à Saúde da Família (NASFs) possibilitaram evidenciar, nas entrevistas, a distinção das atividades realizadas com relação a outras ramificações da atenção primária, uma vez que, para esses profissionais, o atendimento direto aos usuários, individual ou por meio de visita domiciliar, é realizado eventualmente e de forma descontínua.

A natureza do trabalho do Serviço Social no NASF recai, particularmente, para a utilização de abordagem grupal, coletiva, comunitária, mediante a participação em reuniões com a comunidade, com o conselho gestor de saúde, conselho de direitos e na articulação com movimentos sociais e populares locais.

Dentre as atividades realizadas de modo geral pelo NASF, enquanto um serviço de saúde pública que agrega diversas áreas e especializações profissionais, foram destacadas na pesquisa de campo as seguintes: apoio institucional (cadastramento, oficina de acolhimento); atendimento individual em situações específicas e pontuais, considerando a competência do NASF; reuniões com equipe e trabalhos em grupo; matriciamento; articulação intersetorial e com a comunidade; educação permanente; visita domiciliar e institucional; práticas integrativas e Projeto Terapêutico Singular; dentre outros.

No que se refere às atribuições, competências e ações profissionais de assistentes sociais no NASF, a pesquisa de campo identificou: a supervisão de estágio; a formulação e planejamento de políticas sociais; atendimento e orientação aos indivíduos, grupos e famílias; reuniões de equipe; visitas domiciliares e institucionais; estudos e relatórios sociais; execução de políticas sociais; ações de organização, mobilização e participação.

Além disso, foi destacado, nas entrevistas com os respectivos profissionais, a importância do registro das atividades realizadas nos diferentes espaços, assim como das discussões de matriciamento com as Equipes de Saúde da Família.

O registro de dados e informações, com base nos atendimentos realizados, de reuniões em equipe e de matriciamento, além de exigência institucional para apresentar a produtividade, é também um procedimento profissional utilizado como forma de apreensão crítica, teórica e ética a respeito das questões apresentadas no cotidiano.

O desafio é fazer com que a documentação e o registro ultrapassem a finalidade meramente burocrática e contribuam para a análise aprofundada das situações apresentadas e para a viabilização dos direitos sociais. A documentação pode ser utilizada para a reflexão e 
análise do exercício profissional e, especificamente no NASF, pode se constituir em uma ferramenta decisiva para a análise do trabalho realizado pela equipe, e para a construção de estratégias para o aprimoramento das ações cotidianas. Além do mais, pode servir como material de pesquisa e de proposições no planejamento e formulação de políticas públicas e sociais, além de subsidiar na análise das ações do NASF, considerando as especificidades dessa modalidade interventiva.

Os registros, sejam eles realizados a partir de reuniões da equipe do NASF ou com as Equipe de Saúde da Família, são instrumentos importantes na sintetização das ações desenvolvidas pela equipe profissional no atendimento de uma necessidade concreta de sistematização de informações, acompanhamento e comunicação entre profissionais. 0 cuidado recai para o risco de cair na burocratização, pois o registro, em muitas situações no trabalho do NASF, ao tratar com aspectos de vidas humanas, apresenta-se repleto de significados e sentidos e "[...] o Serviço Social nas unidades de saúde trabalha com uma variável de formulários, como: ficha social, evolução social, cartão de cadastramento de acompanhantes, roteiro para visita domiciliar, encaminhamentos etc." (MATOS, 2013, p. 116).

Portanto, não se trata de documentar por documentar, registrar por registrar, do ponto de vista formal-institucional. Para o Serviço Social ${ }^{9}$, o registro, em suas diferentes formas e instrumentos, potencializa a reflexão crítica sobre as situações apresentadas pelas famílias, grupos, indivíduos, e também pode ser utilizado para a viabilização dos serviços e direitos sociais, além de fonte para futuras pesquisas.

O registro do exercício profissional é uma das expressões da materialização da intervenção profissional que, realizada num contexto do trabalho coletivo, terá a sua forma e conteúdo (o registro) também determinado por esse trabalho, ainda que essa não seja a única determinação (MATOS, 2013, p. 119).

Assistentes sociais inseridos na Atenção Primária à Saúde, como no caso do NASF, sob a orientação do projeto ético-político da profissão e das premissas da Reforma Sanitária, têm subsídios para realizar seu trabalho na perspectiva da universalidade de acesso aos direitos, segundo a qual todos devem receber atendimento, independentemente, de raça, etnia, classe social, religião, gênero, credo e orientação sexual. Além disso, é fundamental

\footnotetext{
9 Importante ter como referência nessa discussão, a Resolução CFESS no 493, de 2006, de 21 de agosto de 2006, que dispõe sobre as condições éticas e técnicas do exercício profissional de assistentes sociais.
} 
assegurar a integralidade da assistência por todos os profissionais da saúde visando um atendimento articulado e contínuo das ações e serviços de saúde (MARTINI; DAL PRÁ, 2018).

A integralidade em saúde requer ações e articulações entre os serviços de saúde e outras políticas públicas, o que não representa uma tarefa fácil, diante de uma rede precarizada de serviços em diversas áreas, como educação, cultura, esporte e assistência social.

A articulação entre as redes de serviços do território em suas ações intersetoriais, ou mobilização da própria saúde é uma ação desempenhada por assistentes sociais na atenção primária, a qual pode ser realizada de forma compartilhada com as Equipes de Saúde da Família.

Contudo, a realidade que se apresenta no território é desafiadora, devido à complexidade das demandas de saúde e pela elevada fragilidade da própria rede de saúde, na qual há uma escassa ou quase inexistência de oferta em serviços secundários no Distrito Federal, e ainda, uma enorme dificuldade em acessar a rede de serviços especializados em saúde.

Expressões desta fragilidade foram identificadas no decurso dos relatos de assistentes sociais nas entrevistas, com destaque para a inadequação do número de Equipe de Saúde da Família por NASF, ou seja, excedente ao definido pelo Ministério da Saúde, de modo que inviabiliza o alcance dos objetivos propostos pelo NASF. Tal fato, segundo depoimentos, além de dificultar o processo de trabalho da equipe, contribui na intensificação e precarização das condições de trabalho de assistentes sociais e dos demais profissionais.

A gente dá apoio a 21 equipes e a gente está tentando reduzir para 9, porque o que é preconizado pelo NASF são 9 equipes. A gente está com 21, então não é nem NASF (Assistente social NASF 2).

Esse depoimento também expôs que a inserção da Residência Multiprofissional oportunizou uma redefinição no número de Equipes de Saúde da Família atendidas pelo NASF, passando o acompanhamento de algumas destas Equipes para os residentes. Essa alternativa tende a fortalecer a precarização do trabalho em saúde, devido à prática de substituição do trabalhador formal por profissionais em processo de formação, no caso de residentes. Tal estratégia contribui também para a precarização da educação e para um redirecionamento do processo formativo em saúde, pois, a partir da adesão a essas medidas, o processo pedagógico de aprendizagem do residente torna-se secundarizado, em uma lógica de 
incorporação de sua força de trabalho em substituição ao trabalhador formal, contradizendo a direção político-pedagógica da residência em saúde.

\section{Considerações finais}

Analisar os espaços sócio-ocupacionais de assistentes sociais em sua expansão, contradições e metamorfoses, requer inscrevê-los na totalidade histórica, ao levar em consideração as formas assumidas pelo capital no processo de revitalização da acumulação no cenário da crise mundial.

Desse modo, a compreensão do exercício profissional de assistentes sociais na Atenção Primária à Saúde, com ênfase para os Núcleos de Apoio à Saúde da Família (NASFs), partiu de pressupostos considerando o atual cenário de reestruturação produtiva, de incorporação de medidas de austeridade econômica e de aprofundamento da perspectiva neoliberal, no âmbito das políticas econômicas e sociais, com desdobramentos diretos na política de saúde e, por conseguinte, na atuação da equipe de profissionais de saúde.

Além disso, é fundamental a apreensão das determinações sociais condicionadoras das condições de vida do usuário e suas implicações para o processo saúde-doença, o que possibilita pensar criticamente o exercício profissional de assistentes sociais e nas ações interdisciplinares e intersetoriais do território de intervenção, pois é nesse solo histórico que se agudizam as expressões da "questão social" como o desemprego, as múltiplas formas de violência, a baixa escolarização, as condições precárias de saúde, moradia e saneamento básico, dentre outras. Mas, também é por meio da aproximação com o território que se torna possível estabelecer as relações com usuários, com as famílias, com a comunidade e fomentar as potencialidades para a construção de ações de mobilização e participação dos usuários para a defesa e garantia dos direitos sociais, compreendidos na sua universalidade.

Especificamente sobre o exercício profissional de assistentes sociais no NASF, no âmbito do Distrito Federal, cabe questionar, ao considerar o momento político conjuntural e local, se as mudanças propostas no modelo assistencial em saúde serão implementadas como uma política pública estruturante, ou se seguirão uma tendência de alterações baseadas nos interesses governamentais de natureza particularizada. E ainda, se haverá, de fato, previsão e destinação de recursos orçamentários voltados para o fortalecimento da atenção primária à saúde de qualidade, conforme preconizam os princípios e diretrizes do SUS. 
Com isso, observa-se que são muitos os desafios conferidos ao Serviço Social na atenção primária à saúde, mas também é um momento no qual se apresenta a possibilidade de se afirmar a importância do exercício profissional neste espaço sócio-ocupacional com base no projeto ético-político e sob uma perspectiva de defesa universal dos direitos e da saúde pública.

\section{Referências}

BRASIL. Medida Provisória no 890, de 10 de agosto de 2019. Institui o Programa Médicos pelo Brasil, no âmbito da atenção primária à saúde no Sistema Único de Saúde, e autoriza o Poder Executivo federal a instituir serviço social autônomo denominado Agência para o Desenvolvimento da Atenção Primária à Saúde. Diário Oficial da União: seção 1, Brasília, ano 157, n. 147-A, p. 1, 1 ago. 2019a. Disponível em: http://www.in.gov.br/en/web/dou//medida-provisoria-n-890-de-1-de-agosto-de-2019-208356620. Acesso em: 23 fev. 2020.

BRASIL. Ministério da Saúde. Carteira de Serviços da Atenção Primária à Saúde (CASAPS). Brasília: Ministério da Saúde, 2019b. Disponível em:

http://189.28.128.100/dab/docs/portaldab/documentos/casaps_versao_profissionais_saud e_gestores_completa.pdf. Acesso em: 23 fev. 2020.

BRASIL. Ministério da Saúde. Portaria no 154, de 24 de janeiro de 2008. Cria os Núcleos de Apoio à Saúde da Família - NASF. Brasília: Ministério da Saúde, 2008. Disponível em: http://bvsms.saude.gov.br/bvs/saudelegis/gm/2008/prt0154_24_01_2008.html. Acesso em: 18 set. 2018.

BRASIL. Ministério da Saúde. Portaria no 2.436, de 21 de setembro de 2017. Aprova a Política Nacional de Atenção Básica, estabelecendo a revisão de diretrizes para a organização da Atenção Básica, no âmbito do Sistema Único de Saúde (SUS). Brasília: Ministério da Saúde, 2017. Disponível em:

http://bvsms.saude.gov.br/bvs/saudelegis/gm/2017/prt2436_22_09_2017.html. Acesso em: 20 set. 2018.

BRASIL. Ministério da Saúde. Portaria no 2.488, de 21 de outubro de 2011. Aprova a Política Nacional de Atenção Básica, estabelecendo a revisão de diretrizes e normas para a organização da Atenção Básica, para a Estratégia Saúde da Família (ESF) e o Programa de Agentes Comunitários de Saúde (PACS). Brasília: Ministério da Saúde, 2011. Disponível em: http://bvsms.saude.gov.br/bvs/saudelegis/gm/2011/prt2488_21_10_2011.html. Acesso em: 18 set. 2018.

BRASIL. Ministério da Saúde. Portaria no 648, de 28 de março de 2006. Aprova a Política Nacional de Atenção Básica, estabelecendo a revisão de diretrizes e normas para a organização da Atenção Básica para o Programa Saúde da Família (PSF) e o Programa Agentes Comunitários de Saúde (PACS). Brasília: Ministério da Saúde, 2006. Disponível em: http://bvsms.saude.gov.br/bvs/saudelegis/gm/2006/prt0648_28_03_2006.html. Acesso em: 22 set. 2018. 
BRASIL. Ministério da Saúde. Secretaria de Atenção à Saúde. Departamento de Atenção Básica. Núcleo de Apoio à Saúde da Família: ferramentas para a gestão e o trabalho cotidiano. Brasília: Ministério da Saúde, 2014. v. 1. (Cadernos de Atenção Básica, n. 39).

BRASIL. Ministério da Saúde. Secretaria de Atenção Primária à Saúde. Departamento de Saúde da Família. Nota Técnica no 3/2020-DESF/SAPS/MS. Assunto: Núcleo Ampliado de Saúde da Família e Atenção Básica (NASF-AB) e Programa Previne Brasil. Brasília: Ministério da Saúde, 2019c. Disponível em: https://www.conasems.org.br/wpcontent/uploads/2020/01/NT-NASF-AB-e-Previne-Brasil-1.pdf. Acesso em: 23 fev. 2020.

BRASIL. Portaria no 2.979, de 12 de novembro de 2019. Institui o Programa Previne Brasil, que estabelece novo modelo de financiamento de custeio da Atenção Primária à Saúde no âmbito do Sistema Único de Saúde, por meio da alteração da Portaria de Consolidação no 6/GM/MS, de 28 de setembro de 2017. Diário Oficial da União: seção 1, Brasília, ano 157, n. 220, p. 97, 13 nov. 2019d. Disponível em: http://www.in.gov.br/en/web/dou/-/portaria-n2.979-de-12-de-novembro-de-2019-227652180. Acesso em: 23 fev. 2020.

CAMPOS, Gastão Wagner de Sousa. Equipes de referência e apoio especializado matricial: um ensaio sobre a reorganização do trabalho em saúde. Ciência \& Saúde Coletiva, Rio de Janeiro, v. 4, n. 2, p. 393-403, 1999.

CAMPOS, Gastão Wagner Sousa; DOMITTI, Ana Carla. Apoio matricial e equipe de referência: uma metodologia para gestão do trabalho interdisciplinar em saúde. Cadernos de Saúde Pública, Rio de Janeiro, v. 23, n. 2, fev. 2007.

GÖTTEMS, Leila Bernardo Donato; EVANGELISTA, Maria do Socorro Nantua; PIRES, Maria Raquel Gomes Maia; SILVA, Aline Ferreira Melgaço da; SILVA, Priscila Avelino da. Trajetória da política de atenção básica à saúde no Distrito Federal, Brasil (1960 a 2007): análise a partir do marco teórico do neo-institucionalismo histórico. Cadernos de Saúde Pública, Rio de Janeiro, v. 25, n. 6, p. 1409-1419, jun. 2009.

IAMAMOTO, Marilda Vilela. Os espaços sócio-ocupacionais do assistente social. In: CONSELHO FEDERAL DE SERVIÇO SOCIAL - CFESS; ASSOCIAÇÃO BRASILEIRA DE ENSINO E PESQUISA EM SERVIÇO SOCIAL - ABEPSS. Serviço Social: direitos sociais e competências profissionais. Brasília: CFESS: ABEPSS, 2009. p. 341-375.

MARTINI, Débora; DAL PRÁ, Keli Regina. A inserção do assistente social na atenção primária à saúde. Argumentum, Vitória, v. 10, n. 1, p. 118-132, jan./abr. 2018.

MATOS, Maurilio Castro de. Serviço Social, ética e saúde: reflexões para o exercício profissional. São Paulo: Cortez, 2013.

MENDES, Eugênio Vilaça. A construção social da atenção primária à saúde. Brasília: Conselho Nacional de Secretários de Saúde, 2015.

PONTES, Reinaldo. Mediação e Serviço Social: um estudo preliminar sobre a categoria teórica e sua apropriação pelo Serviço Social. 6. ed. São Paulo: Cortez, 2009. 
RAICHELIS, Raquel. O assistente social como trabalhador assalariado: desafios frente às violações de seus direitos. Serviço Social e Sociedade, São Paulo, n. 107, p. 420-437, jul./set. 2011.

SANTOS, Claudia Monica. Na prática a teoria é outra? Mitos e dilemas na relação entre teoria, prática, instrumentos e técnicas no Serviço Social. Rio de Janeiro: Lumen Juris, 2010.

TRINDADE, Rosa Lúcia Prédes. Ações profissionais, procedimentos e instrumentos no trabalho dos assistentes sociais nas políticas sociais. In: SANTOS, Cláudia Mônica dos; BACKX, Sheila; GUERRA, Yolanda (org.). A dimensão técnico-operativa no Serviço Social: desafios contemporâneos. Juiz de Fora: UFJF, 2012. p. 69-102.

TRINDADE, Rosa Lúcia Prédes. Tendências do mercado de trabalho do Serviço Social: descobertas e inquietações a partir da pesquisa sobre a realidade de Alagoas (1998-2010). In: TRINDADE, Rosa Lúcia Prédes; LINS, Maria Alcina Terto. Assistente social: trabalhador assalariado: fundamentos teóricos e históricos para uma análise crítica. Maceió: EDUFAL, 2015. p. 119-146. 